\title{
Rhenium and iridium targets prepared using a novel graphene loading technique
}

\author{
John P. Greene ${ }^{1, *}$, Matthew Gott ${ }^{1}$, Richard L. Fink ${ }^{2}$, and Igor Pavlovsky ${ }^{2}$ \\ ${ }^{1}$ Physics Division, Argonne National Laboratory, Lemont, Illinois, United States \\ ${ }^{2}$ Applied Nanotech, Inc., Austin, Texas, United States
}

\begin{abstract}
For accelerator targets, graphene films are an excellent material choice due to their high thermal conductivity, high temperature tolerance, low outgassing, mechanical integrity, and ease of handling. A variety of targets have been produced using graphene material as a backing or a host matrix. One of the unique advantages of the graphene film fabrication process is the capability to embed target materials, including refractory metals, in the nanoparticle form into a host graphene matrix during target preparation. Targets of natIr and nat Re have been fabricated as nanoparticle loaded graphene targets for use in nuclear physics research. We have obtained beam time to evaluate target performance as well as production yields and nuclear decay properties via the ${ }^{n a t} \operatorname{Re}(\mathrm{a}, 2 \mathrm{n}){ }^{186} \mathrm{Ir}$ and ${ }^{\text {nat }} \operatorname{Ir}(\mathrm{a}, 3 \mathrm{n}){ }^{194} \mathrm{Au}$ reactions, respectively. These rhenium and iridium targets will be irradiated using the ATLAS accelerator and gamma rays measured in-place using the highprecision gamma-ray spectroscopy capabilities of Gammasphere and further analyzed using a multiparameter detector system. Future plans include the preparation of isotopic targets of these two elements.
\end{abstract}

\section{Introduction and motivation}

With cancer incidence rates continuing to climb, research into advanced, diagnostic and therapeutic radiopharmaceuticals is critical to meeting future needs [1]. In this regard, a theranostic drug allows for low dose imaging and dosimetry estimates followed by a tailored course of therapeutic treatments based on the diagnostic evaluation. The success of this approach is dependent on high specific activity radionuclides. Some recent studies into iridium-based anti-cancer drugs have used photosensitizing complexes to attack cancer cells [2-4]. Incorporation of the Auger-emitting ${ }^{186} \operatorname{Ir}\left(\mathrm{t}_{1 / 2}=16.64 \mathrm{~h}\right)$ could lead to a synergistic killing effect improving the overall treatment by reducing the required dose of the chemotherapeutic agent. Additionally, its gamma emissions ( $\gamma=296.9 \mathrm{keV}, 62.3 \%$; $137.2 \mathrm{keV}, 41.4 \%$ ) are suitable for SPECT imaging and could have an immense impact on determining dose and clearance characteristics. Cytotoxic gold compounds have also been evaluated as anti-cancer drugs [5]. Auger-emitting ${ }^{194} \mathrm{Au}\left(\mathrm{t}_{1 / 2}=38.02 \mathrm{~h}\right)$ can provide the same synergistic killing effect and SPECT imaging $(\gamma=328.5 \mathrm{keV}$, $60.4 \% ; 293.5 \mathrm{keV}, 10.6 \%$ ) for gold-based anti-cancer drugs.

The experiment described here would attempt to produce high specific activity radio-iridium and -gold

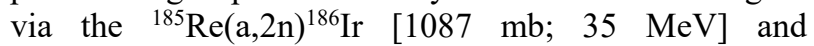
${ }^{193} \operatorname{Ir}(\mathrm{a}, 3 \mathrm{n}){ }^{194} \mathrm{Au} \quad[1101 \mathrm{mb} ; 35 \mathrm{MeV}]$ reactions, respectively. Though we will utilize natural abundance targets in these initial experiments, these isotopes are highly naturally abundant $\left(37.40 \%\right.$ for ${ }^{185} \operatorname{Re}$ and $62.7 \%$ for ${ }^{193} \mathrm{Ir}$ ). To date, experimental data in the EXFOR database is extremely limited for these reactions, particularly at the alpha energy of interest. Most the data relies on measurements performed during the 1990s [6-9]. Theoretical production yields were calculated based on a $1 \mathrm{mg} / \mathrm{cm}^{2}$ target and a beam current of $1 \mathrm{pnA}$. Production rates of $12.9 \mu \mathrm{Ci} / \mathrm{nAh}$ and $20.8 \mu \mathrm{Ci} / \mathrm{nAh}$ are expected for ${ }^{186} \mathrm{Ir}$ and ${ }^{194} \mathrm{Au}$, respectively.

\section{Description of the graphene loading technique}

Rhenium was first discovered in platinum ores by Noddack, Tacke and Beer in 1925 [10]. The origin of the name comes from the Greek word "Rhenus" meaning river "Rhine." Rhenium does not occur free in nature or as a compound or mineral though it is widely spread throughout the earth's crust at a concentration of 0.001 ppm. The element is silvery-white with a metallic luster and when annealed, rhenium is very ductile and can be bent, coiled or rolled. Its atomic weight is 186.2 , density of $21.02 \mathrm{~g} / \mathrm{cm}^{3}$ and a melting point of $3180^{\circ} \mathrm{C}$. The isotopes are ${ }^{185} \mathrm{Re}$ at $37.40 \%$ and ${ }^{187} \mathrm{Re}$ at $62.60 \%$ natural abundance, respectively and available as highly enriched metal powder.

Iridium was discovered in 1803 by Tennant [10] in residue left from platinum dissolved in aqua regia and the name is derived from its salts which are highly colored. It occurs uncombined in nature and is found with platinum in alluvial deposits. The element is white, similar to Pt but with a slight yellowish cast and is hard

\footnotetext{
*Corresponding author: greene@anl.gov
} 
and brittle making it difficult to machine, form or work. Iridium is the most corrosion resistant metal known. Its physical properties include; atomic weight 192.22, a melting point of $2410^{\circ} \mathrm{C}$ and a density of $22.42 \mathrm{~g} / \mathrm{cm}^{3}$. There are two naturally occurring isotopes; ${ }^{191} \mathrm{Ir}$ with $37.3 \%$ natural abundance and ${ }^{193}$ Ir with $62.7 \%$ natural abundance. They are also available as highly enriched metal powder.

Maier-Komor first reported on the preparation of Re targets on thin carbon backings by the method of electron bombardment [11] and similarly by Demaret onto aluminum backings [12]. Rhenium metal is also easily rolled. Isotopically enriched iridium targets have been prepared by McDaniel (et al.) [13]. Richaud produced targets via a centrifugal method [14] and Kobisk (et al.) suggested preparing, for example, ruthenium and iridium targets by embedding in a Cermet matrix [15]. Iridium, like osmium is too brittle to be rolled or formed.

The refractory metal targets are notoriously difficult to produce due to their extremely high melting points. Applied Nanotech, through an SBIR (Small Business Innovation Research), has developed a novel method to produce thin refractory metal targets imbedded in a graphene matrix and contain 1:1 metal: carbon by weight [16]. As these with rhenium and iridium loaded graphene targets have never been exposed to heavy-ion beam irradiation, testing their in-beam stability and performance was necessary. The targets were therefore first bombarded with $0.5 \mathrm{pnA} \alpha$ beam to evaluate target integrity and to produce activity for gamma spectroscopy before enabling higher power irradiation.

One of the unique advantages of this new process is the capability to embed target materials, including the refractory metals, in the nanoparticle form into a graphene film during the film fabrication. Iridium nanoparticle dispersions were prepared in ethylene glycol by reduction of hexachloroiridate $\left(\mathrm{H}_{2} \mathrm{IrCl}_{6} * \mathrm{H}_{2} \mathrm{O}\right)$ at elevated temperatures up to $150^{\circ} \mathrm{C}$. The average particle obtained was in the range of $170 \mathrm{~nm}$ to $600 \mathrm{~nm}$ with the particle size distribution measured using a Nanotrac particle analyzer. Also, a sample of Ir nanoparticles was purchased from American Elements having nanoparticles with average size of $<100 \mathrm{~nm}$. The material was dispersed in deionized water water to obtain $10 \mathrm{mg} / \mathrm{ml}$ Ir stock dispersion.

To prepare Ir-loaded targets, the nat Ir nanoparticle dispersions were added and mixed with the prepared graphene solutions before the final filtration. A range of different thicknesses and loadings of Ir in the graphene matrix were obtained. To ensure that the Ir-loaded graphene targets keep good mechanical integrity in beam, the mass loading of Ir of 1:1 over graphene was not exceeded (higher Ir loadings might interfere with van der Waals attraction forces between graphene crystallites). Area densities of the obtained films were in the range of 0.4 to $0.6 \mathrm{mg} / \mathrm{cm}^{2}$.
Several $22 \mathrm{~mm}$ diameter ${ }^{\text {nat }}$ Ir targets were made from dispersions using a $125 \mathrm{~mm}$ syringe pump-based pressure filtration system (Fig. 1). The filtration systems and polymer filters were purchased from Cole Parmer. The targets have Ir loading of 1:1 with respect to the mass of graphene, where the areal mass density of graphene was in the range of 0.2 to $0.3 \mathrm{mg} / \mathrm{cm}^{2}$. Quadratic samples of $40 \times 40 \mathrm{~mm}^{2}$ were then cut from the $125 \mathrm{~mm}$ disk samples to prepare targets.



Fig. 1 Stainless steel, one inch diameter pressure filtration system

This process was repeated to produce graphene targets loaded with ${ }^{\text {nat }} \mathrm{Re}$ nanoparticles. To prepare Re nanoparticles, ammonium perrhenate (APR) powder, purchased from Sigma Aldrich, was reduced in a tube furnace. Approximately $0.5 \mathrm{~g}$ of this APR powder was spread uniformly over $10 \mathrm{~cm}^{2}$ of a tungsten boat. The boat was then moved into the center of the tube furnace, and $100 \mathrm{sccm} \mathrm{N}_{2}$ flow was used to purge the tube for 20 minutes. The oven temperature was then ramped at $10{ }^{\circ} \mathrm{C} / \mathrm{m}$ to $320{ }^{\circ} \mathrm{C}$, and held at this temperature for 1 hour. After dark gray $\mathrm{ReO}_{2}$ was formed in the boat, $50 \mathrm{sccm} \mathrm{H} \mathrm{H}_{2}$ was introduced to further reduce the rhenium oxide to metal powder at the same temperature for another 2 hours. The aqueous powder dispersion was then processed in a SpeedMixer and sonicated. Natural rhenium targets were produced the same way as Ir targets, using a 1 inch diameter stainless steel pressure filtration system. Table 1 lists the Re and Ir targets that were prepared on target frames and used for beam irradiation (Fig. 2). Future plans include producing these graphene targets using enriched isotopes available from Oak Ridge National Laboratory. 


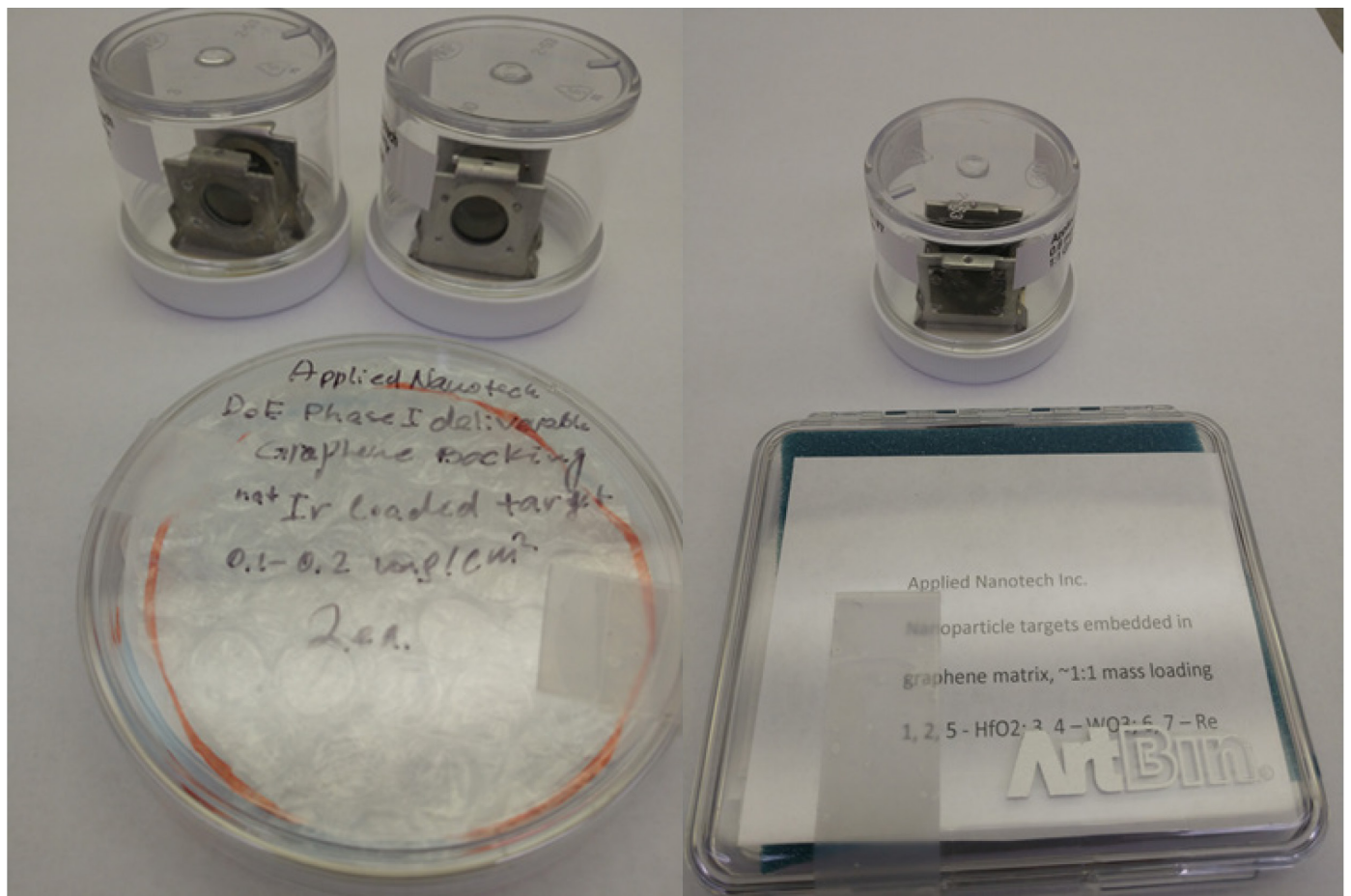

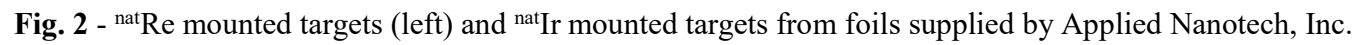

Table 1. Prepared Targets and Thicknesses

\begin{tabular}{|c|c|c|}
\hline TARGET & $\begin{array}{c}\text { TARGET } \\
\text { THICKNESS } \\
\left(\mathrm{mg} / \mathrm{cm}^{2}\right)\end{array}$ & $\begin{array}{c}\text { NUMBER } \\
\text { OF } \\
\text { TARGETS }\end{array}$ \\
\hline${ }^{\text {nat }} \mathrm{Re}$ & $0.6(0.3 \mathrm{Re}+0.3 \mathrm{C})$ & 2 \\
\hline $\begin{array}{l}\text { nat Ir (American } \\
\text { Elements) }\end{array}$ & $0.4(0.2 \mathrm{Ir}+0.2 \mathrm{C})$ & 4 \\
\hline${ }^{\text {nat }} \operatorname{Ir}(\mathrm{ANI})$ & $0.6(0.3 \mathrm{Ir}+0.3 \mathrm{C})$ & 4 \\
\hline
\end{tabular}

\section{Experimental results and discussion}

Two days of requested beam time were used for evaluation of ${ }^{186} \mathrm{Ir}$ and ${ }^{194} \mathrm{Au}$ excitation functions and production yields via the ${ }^{n a t} \operatorname{Re}(\mathrm{a}, 2 \mathrm{n}){ }^{186} \mathrm{Ir}$ and ${ }^{\text {nat }} \operatorname{Ir}(\mathrm{a}, 3 \mathrm{n}){ }^{194} \mathrm{Au}$ reactions, respectively. Irradiation of these novel rhenium- and iridium-loaded graphene targets was accomplished using the ATLAS superconducting accelerator by two methods. First, with single targets in-beam experiments providing measurement of the decay gamma rays using the highprecision gamma-ray spectroscopy capabilities of Gammasphere. Next, a set of targets were arranged in a "stack" using $\mathrm{Cu}$ foils interlaced between the Ir and Re targets to degrade the beam energy - providing also a known flux determination for later cross-sectional data extraction. For this, several $\mathrm{Cu}$ foil targets with thicknesses of $2.2 \mathrm{mg} / \mathrm{cm}^{2}$ and $4 \mathrm{mg} / \mathrm{cm}^{2}$ were first prepared by mechanical rolling [17]. This target stack was bombarded for 5 hours at 5 pnA of alpha beam with energies between 32-38 MeV, degrading as it traverses the target stack. After beam bombardment, the target stack was disassembled, enabling the measurement of an excitation function of this reaction using several targets of each element. Examination of the targets after irradiation showed no visual damage (Fig. 3).

The ${ }^{194} \mathrm{Au}$ and ${ }^{186} \mathrm{Ir}$ reaction products themselves will be stopped inside the targets, which can be used for inbeam and off-line activity measurements. Using in-beam detection of prompt gammas, we can determine the production rates for the stable isotopes in addition to those of the radioisotopes. This is critical for determining the specific activity and purity of the produced medical isotopes and is useful in testing model predictions. In-place determinations of the target activities at EOB was done using Gammasphere. In order to quantify the absolute gamma efficiency for these measurements, a calibrated standard source was located next to the target within the experiment chamber. The gamma rays from the reaction products and from this known source were then measured at the same time, providing high-precision gamma spectroscopy data. The gamma intensities from each Gammasphere run can be used to precisely calculate the production yields and determine the reaction cross-sections at the degraded beam energy. Some data was also collected with both $\mathrm{Cu}$ and Ir targets at the same time to determine if this method can be used for similar measurements with other reactions in the future. These offline decay measurements enabled validation of production rates and provide a baseline count for further irradiations. 


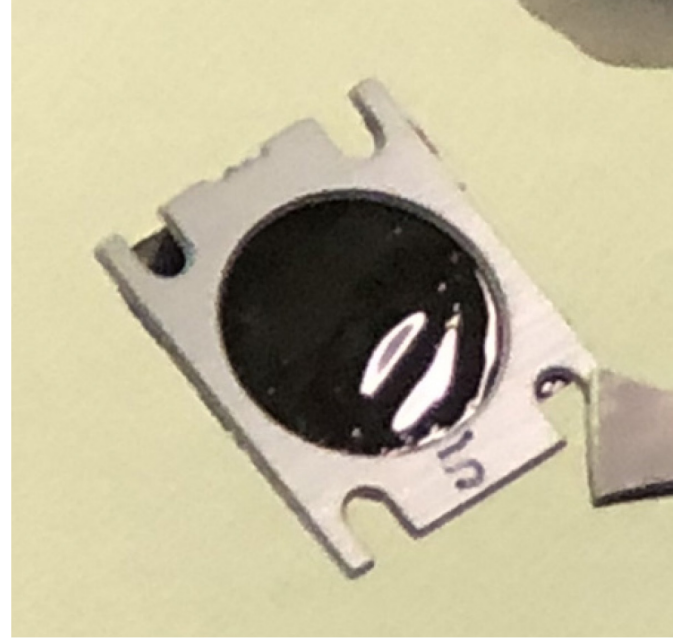

Fig. 3 nat Ir-loaded graphene target, $0.6 \mathrm{mg} / \mathrm{cm}^{2}$, after beam irradiation

\section{Conclusion}

One of the unique advantages of the graphene film fabrication process is the capability to embed target materials, including refractory metals, in the nanoparticle phase into a host graphene matrix during target preparation. ${ }^{\text {nat } I r, ~}{ }^{\text {nat }} \mathrm{Re}$, as described above, and ${ }^{\text {nat }} \mathrm{WO}_{3}$, and ${ }^{\text {nat }} \mathrm{HfO}_{2}$ nanoparticle-loaded graphene targets were fabricated for use in nuclear physics research. Thin graphene/refractory metal targets with thicknesses of $0.4-0.6 \mathrm{mg} / \mathrm{cm}^{2}$ were produced. The targets were easy to handle and to attach to Gammasphere target frames. Targets of nat Re and nat Ir were successfully irradiated without being damaged and the gamma-rays measured offline were used to determine production cross sections for the radionuclides of interest. The resulting cross sections, impurity production rates, and potential thick isotopic target production yields will be forthcoming.

This material is based upon work supported by the U.S. Department of Energy, Office of Science, Office of Nuclear Physics, under Award Number DE-SC-0017208 and Contract No. DE-AC02-06CH11357. This research used resources of ANL's ATLAS facility, which is a DOE Office of Science User Facility.

This report was prepared as an account of work sponsored by an agency of the United States Government. Neither the United States Government nor any agency thereof, nor any of their employees, makes any warranty, express or implied, or assumes any legal liability or responsibility for the accuracy, completeness, or usefulness of any information, apparatus, product, or process disclosed, or represents that its use would not infringe privately owned rights. Reference herein to any specific commercial product, process, or service by trade name, trademark, manufacturer, or otherwise does not necessarily constitute or imply its endorsement, recommendation, or favoring by the United States Government or any agency thereof. The views and opinions of authors expressed herein do not necessarily state or reflect those of the United States Government or any agency thereof.

\section{References}

1. Meeting Isotope Needs and Capturing Opportunities for the Future: The 2015 Long Range Plan for the DOE-NP Isotope Program, NSAC Isotopes Subcommittee, July 2015

2. P Zhang, CKC Chiu, H Huang, et al., Angew. Chem. Int. Ed., 56, 14898-14902 (2017)

3. N Wu, J-J Cao, X-W Wu, et al., Dalton Trans. 46, 13482-13491 (2017)

4. H Xiang, H Chen, HP Tham, et al., ACS Appl. Mater. Interfaces 9, 27553-27562 (2017)

5. L Messori, F Scaletti, L Massai, et al., Chem. Commun., 49, 10100-10102 (2013)

6. M Ismail, Pramana J. Phys., 50(2), 173-189, (1998)

7. JD Stickler, KJ Hofstetter, Phys. Rev. C, 9 (3), 1064-1071 (1974)

8. MK Bhardwaj, IA Rizvi, AK Chaubey, Phys. Rev. C, 45 (5), 2338-2342 (1992)

9. T Szuecs, GG Kiss, Gy Gyuerky, et al., Phys. Rev. C 776, 396-401 (2018)

10. RC Weast (1980) Handbook of Chemistry and Physics, $56^{\text {th }}$ ed. CRC Press, Cleveland

11. P Maier-Komor, Proceedings of the 1974 Annual Conference of the INTDS, Chalk River, Ontario, 70 (1974)

12. Demaret, INTDS Newsletter Vol. 20 No. 1, 7 (1993)

13. EW McDaniel, Proceedings of the 1974 Annual Conference of the INTDS, Chalk River, Ontario, 151 (1974)

14. JP Richaud, Nucl. Instr. and Meth. 167 ,91 (1979)

15. EH Kobisk, TC Quinby and WS Aaron, Preparation of Nuclear targets for Particle Accelerators, J Jaklovsky, Ed. Plenum Press, New York, 127 (1981)

16. To be published

17. FJ Karasek, Nucl. Instr. and Meth. 102 , 457 (1972) 